OPEN ACCESS

Edited by:

Javier Ochoa-Reparaz,

Eastern Washington University,

United States

Reviewed by:

Shailesh K. Shahi,

University of lowa, United States

Gislane Lelis Vilela de Oliveira,

São Paulo State University, Brazil

*Correspondence:

Xin M. Luo

xinluo@vt.edu

Specialty section: This article was submitted to

Mucosal Immunity,

a section of the journal

Frontiers in Immunology

Received: 13 July 2018 Accepted: 19 November 2018 Published: 03 December 2018

Citation:

Swartwout B and Luo XM (2018) Implications of Probiotics on the

Maternal-Neonatal Interface: Gut

Microbiota, Immunomodulation, and

Autoimmunity

Front. Immunol. 9:2840.

doi: 10.3389/fimmu.2018.02840

\title{
Implications of Probiotics on the Maternal-Neonatal Interface: Gut Microbiota, Immunomodulation, and Autoimmunity
}

\section{Brianna Swartwout ${ }^{1}$ and Xin M. Luo ${ }^{2 *}$}

${ }^{1}$ Translational Biology, Medicine, and Health Graduate Program, Virginia Tech Carilion Research Institute, Virginia Tech, Roanoke, VA, United States, ${ }^{2}$ Department of Biomedical Sciences and Pathobiology, Virginia-Maryland College of Veterinary Medicine, Virginia Tech, Blacksburg, VA, United States

Probiotics are being investigated for the treatment of autoimmune disease by re-balancing dysbiosis induced changes in the immune system. Pregnancy is a health concern surrounding autoimmune disease, both for the mother and her child. Probiotics for maternity are emerging on the market and have gained significant momentum in the literature. Thus far, evidence supports that probiotics alter the structure of the normal microbiota and the microbiota changes significantly during pregnancy. The interaction between probiotics-induced changes and normal changes during pregnancy is poorly understood. Furthermore, there is emerging evidence that the maternal gut microbiota influences the microbiota of offspring, leading to questions on how maternal probiotics may influence the health of neonates. Underpinning the development and balance of the immune system, the microbiota, especially that of the gut, is significantly important, and dysbiosis is an agent of immune dysregulation and autoimmunity. However, few studies exist on the implications of maternal probiotics for the outcome of pregnancy in autoimmune disease. Is it helpful or harmful for mother with autoimmune disease to take probiotics, and would this be protective or pathogenic for her child? Controversy surrounds whether probiotics administered maternally or during infancy are healthful for allergic disease, and their use for autoimmunity is relatively unexplored. This review aims to discuss the use of maternal probiotics in health and autoimmune disease and to investigate their immunomodulatory properties.

Keywords: probiotics, gut microbiota, maternal, neonatal, autoimmunity

\section{INTRODUCTION}

Probiotic based therapies are emerging in modern medicine and have turned the heads of multiple large pharmaceutical companies to treat diseases associated with gut dysbiosis including colorectal cancer, multiple sclerosis (MS), inflammatory bowel disease (IBD), rheumatoid arthritis (RA), systemic lupus erythematosus (SLE), and obesity (1-4). Probiotics provide the potential to compensate for the pathological problems of gut dysbiosis and restore balance to the microbiota of the intestinal tract (5).

The definition of a "probiotic" was formed at The Lactic Acid Bacteria Industrial Platform in 1988 (6), acknowledged in joint consultation of the World Health Organization and Food and 
Agriculture Organization (7), and reapproved in 2014 by a panel of scientist in the International Scientific Association for Probiotics and Prebiotics (8). It resounds throughout literature as an organism that, when delivered in an adequate dose, confers a health benefit beyond normally acquired nutrition $(1,2,9)$. Since the discovery of probiotics, a whole slew of healthy gutpromoting microbe-associated products are being investigated that fall under the umbrella term "pharmabiotics." Besides probiotics, pharmabiotics include prebiotics, synbiotics, and metabolites (1). Another non-living pharmabiotic has recently been described as "paraprobiotic" or "ghost probiotic." Ghost probiotics are comprised of dead cells and bacterial metabolites and named for the interaction with living organisms of nonliving material that was once a living microbe $(10,11)$.

This review does not focus on all of the aforementioned probiotic related products, but galvanizing research is being conducted on how metabolites from probiotics can confer protective effects upon their host. Recently, Lactobacillus acidophilus bacteriocin was proven to inhibit the growth of opportunistic pathogens Gardnerella vaginalis, Streptococcus agalactiae, and Pseudomonas aeruginosa which are also commensal (12). Metabolites isolated from cultured Bacillus coagulans drove maturation of monocytes (13). Short chain fatty acids, like butyrate, are another metabolic derivative of probiotics that are implicated in reducing disease severity in cancer and autoimmunity $(14,15)$. Butyrate has been shown to regulate the diversity of bacteria species in the gut as well as improve the function of the intestinal epithelial layer (16). Cell surface components and supernatant containing bacterial metabolites differentially stimulate immune cells by prompting either proor anti-inflammatory cytokine production (17). Therefore, metabolites perform a variety of beneficial functions including antimicrobial activity, enhancing the gut barrier, modulating microbiota diversity, and immunomodulation, all of which are implicated in the amelioration of autoimmune disorders. A detailed discussion on how bacterial metabolites may affect health and autoimmune diseases can be found elsewhere $(14,18)$.

Current clinical trials involving probiotics include using pet dogs to modulate the microbiota in a probiotic capacity in the elderly, prevention of necrotizing enterocolitis in preterm infants, and intervention for anxiety and depression (19-21). The only clinical trials investigating probiotics in autoimmunity are two studies on type 1 diabetes $(22,23)$, and one study on IgA Nephropathy (24). While the benefits of probiotics for intervention of gut dysbiosis are established, all angles of probiotic use need to be closely examined. Here we review probiotics influence on the gut microbiota, immune system, and autoimmunity in the normal, maternal, and fetal context.

\section{PROBIOTICS}

\section{Changes to Gut Microbiota}

Ten trillions of microbes inhabit the human gastrointestinal tract, the majority of which are bacteria (25). Difference in the gut microbiota occurs throughout the gastrointestinal tract. From the oral cavity to the colon, the microbiota changes.
The esophagus, duodenum, and jejunum contain Streptococcus as the predominant genus, whereas the stomach is colonized by Streptococcus and Prevotella $(25,26)$. However, individuals who are carriers for the species Helicobacter pylori in their stomach have more bacteria from the phylum Proteobacteria $(25,26)$. The colon contains the richest diversity and highest abundance of bacteria, the bulk of which are from the phyla Firmicutes and Bacteroidetes $(25,26)$. Firmicutes is mostly comprised of gram positive species from several notable genera like Enterococcus, Helicobacterium, Streptococcus, Staphylococcus, Lactobacillus, Clostridium, Lachnospireceae, and Streptococcus (27). The phylum Bacteroidetes is comprised of gram negative rods, of which the most notable genera found in the gastrointestinal tract are Bacteroides and Prevotella (28). Differences in microbial populations also exist between the lumen and epithelium. A study using fluorescent in situ hybridization on sections of the colon showed that from the epithelium to the lumen the diversity of bacteria increased (26, 29). In the distal colon, a layer of interlaced bacteria barred the mucosa from Bacteroides and Clostridium difficile $(26,29)$. No bacterial probes hybridized with the mucosa itself, but bacteria present in the crypts-Lactobacillus, Coriobacterium, Phascolarcotbacterium, Clostridium, and assorted Proteobacteria genera-were also present in the interlaced layer and luminal content $(26,29)$. All of the bacteria in the interlaced layer, which included all those found in crypts as well as more species of Clostridium and some Bacteroides, were also found in the lumen $(26,29)$. The luminal content contained the highest number of different bacteria and included prominent genera such as Bifidobacterium and Enterobacteriaceae (26, 29). Other techniques of analyzing mucosa-associated microbes include washing away the luminal content and scraping the mucosa under sterile conditions or do not include the cross-sectional refinement of the aforementioned study $(30,31)$.

As an organ, the health of normal gut microbiota can be enhanced by probiotics. Probiotics have the capacity to antagonize harmful bacteria in the gut by secretion of antimicrobials, competitive adherence to the mucosa, strengthening of the epithelial layer, and modulation of the immune system (9). Probiotics have been shown to stabilize bacterial populations during changes in diet (32) and at the same time change the architecture of the gut microbiota (33). Probiotic mixtures of Lactobacillus, Bifidobacterium, and Streptococcus species alter the landscape of the gut microbiota by increasing the number of Firmicutes and Actinobacteria while decreasing the number of Bacteroidetes and Proteobacteria (33-35). This same shift in bacterial populations is seen both in healthy controls as well as diseased individuals (36). Probiotics increase the number of Lactobacilli and Bifidobacteria secreted in feces, indicating their capacity for colonization of the human gut, which can be enhanced by coating the bacteria in a capsule that protects them from the gastroduodenal environment (37). In colorectal cancer patients, treatment with Lactobacillus acidophilus, Bifidobacterium longum, and Enterococcus faecalis decreased the abundance of pathogenic Fusobacterium, the prevalence of which is associated with both IBD and colorectal cancer (2). Besides influencing bacterial 
populations of the gut, probiotics may also ameliorate diseaseassociated imbalances in the fungal microbiota. A recently published study showed a probiotic mixture of Lactobacillus rhamnosus and Bifidobacterium animalis decreased serum IgG levels against Candida albicans in schizophrenia associated dysbiotic conditions (38).

Most studies with probiotics involve using them either on patients or animal models of disease. The challenge is to delineate how different species and genera impact the normal gut microbiota. For example, treatment of obese mice on a high fat diet with two strains of Lactobacillus, L. curvatus and $L$. plantarum, changed the microbiota by increasing Lactobacillus species, Clostridiales including Ruminococcaceae and Lachnospiraceae, and Bifidobacterium (39). Other studies in mice found that treatment with $L$. acidophilus may have decreased the abundance of Lactobacillus (40). Increases of Lachnospiraceae with Lactobacillus treatment was supported in a study on L. rhamnosus GG (LGG) treatment of patients with cirrhosis that found increases in Lachnospiraceae and Incertae sedis Clostridia XIV, while the abundance of Enterobacteriaceae and Porphyromonadaceae decreased (41). This study did not describe any changes to Lactobacillaceae. Intervention with Bifidobacterium bifidum at the phylum level increased the ratio of Firmicutes to Bacteroidetes, and at the genus level decreased Bacteroides, Faecalibacterium, and Lachnospira with increasing Ruminococcus, Dorea, and Streptococcus (42). Interesting, directly post intervention there was a transient rise in Bacteroides and Lachnospira before the abundance decreased. Thus, while it is difficult to account for difference in dose and disease, probiotic Lactobacillus and Bifidobacterium differentially alter the gut microbiota leading to the conclusion that selection of probiotics must consider the pathology of dysbiosis.

\section{Modulation of Immune System}

Most probiotic strains of bacteria are gram positive bacteria, meaning that they will interact with Toll-like receptor (TLR)2 , responsible for recognition of bacterial peptidoglycan, and produce pro-inflammatory cytokines, such as IL-6 $(43,44)$. Several studies have shown that TLR2 is upregulated in macrophages and epithelial cells after treatment with probiotic species (45-47). Paradoxically, TLR2 stimulation is known to activate NF-kB through a tyrosine kinase dependent manner (48), but NF-kB signaling, along with resulting pro-inflammatory cytokine expression, has been shown to be downregulated with probiotic treatment with these bacteria $(49,50)$. Ryu et al. showed that, in mice, pathological consequences of $C$. rodentium infection is decreased by pretreatment with LGG. Although the study showed that histological and mortality was not improved in TLR2 knockout (KO) or TLR4 KO, pro-inflammatory TNF$\alpha$, IFN- $\gamma$, and MCP- 1 were downregulated in the TLR4 KO, but not the TLR2 KO (51). Therefore, down regulation of pro-inflammatory cytokine production resultant from activation of NF-kB may be dependent on TLR2 stimulation. Actually, probiotic treatment upregulates anti-inflammatory molecules such as IL-10 and TGF- $\beta$ and downregulates pro-inflammatory molecules such as IL-8, IL-1 $\beta$, and TNF- $\alpha(46,52)$. Yet, probiotics do not completely truncate pro-inflammatory signaling as upregulation of IFN- $\gamma$ and IL-2 was observed in the Peyer's patches of mice treated with $L$. casei supplemented yogurt (53), and they have been shown to enhance phagocytic activity of granulocytes and monocytes (54). Taken together, these studies suggest that the anti-inflammatory effects of probiotics may be due the development of immune tolerance by a refined modulation of pattern recognition receptor (PRR) activation or by another mechanism altogether.

Probiotics also modulate the adaptive immune system by increasing the ratio of regulatory to effector $\mathrm{T}$ cell populations (52, 55-58). One putative mechanism of increasing T regulatory (Treg) cells is through inducing regulatory dendritic cells (DCs), which were determined via co-culture by Kwon et al. to cause differentiation of $\mathrm{T}$ cells into inducible Treg (iTreg) cells in peripheral tissue by upregulating forkhead box P3 (Foxp3) (52, 56, 59). The upregulation of Treg cells occurs concomitant with suppression of effectors cells such as T-helper (Th)1, Th2, and Th17 (60). Imbalances in these populations associated with disease are restored by probiotics $(55,61)$. Furthermore, some probiotics beneficially enhance $B$ cell responses. Asthma patients treated with Clostridium butyricum enhanced immunotherapy by improving serum-specific IgE, increasing IL-10 producing B cells, and enhancing antigen specificity in peripheral blood B cells (62). A strain of heat killed L. paracasei isolated from a human adult induced increases in antigen-specific IgA production in mice as well as increases in $\mathrm{T}$ follicular helper (Tfh) cells (63). L. plantarum strain AYA was similarly found to increase differentiation of IgA producing B cells into plasma cells resulting in increased IgA production in the small intestine and lung, thus providing protection against infections (64). Altogether, probiotics induce regulation of the immune system by promoting shifts in lymphocyte populations and promotion of an antiinflammatory environment.

\section{Effect on Autoimmunity}

Autoimmune disorders are believed to result from genetic predisposition and interactions with the environment (65, 66). Dysregulation of commensal microbial communities and interactions with pathogens are an emerging hallmark of autoimmune disease (67). Many autoimmune disorders have recently been associated with gut dysbiosis including SLE, type 1 diabetes, RA, and MS (68-71). Some autoimmune disorders are thought to be catalyzed through molecular mimicry by microbes. For example, $50-70 \%$ of cases of Guillain-Barré syndrome, an autoimmune condition and complication of Zika virus infection, occur after either a respiratory or gastrointestinal infection (72). Instances of Guillain-Barré have been associated with Zika virus, Campylobacter jejuni, cytomegalovirus, Epstein-Barr virus, measles, influenza A, and Mycoplasma pneumoniae (72). Acute rheumatic fever, another autoimmune driven illness, occurs after Streptococcus pyogenes infection (66). Arthritis has also been associated with infection of gut pathogens such as Shigella, Salmonella, Yersinia, and Campylobacter and synovial fluid has been found to contain antigens from these pathogens $(73,74)$.

Disrupting autoimmune disorders through probiotic intervention has generated a lot of interest as a healthcare strategy for chronic autoimmune disorders such as SLE (75). 
Our lab has shown that Lactobacillus species can beneficially impact the progression of glomerulonephritis, an inflammatory kidney syndrome occurring in over half of all SLE patients, in $\mathrm{MRL} / \mathrm{lpr}$ mice (61). Other labs have shown the beneficial effects of probiotics on SLE in NZB/W F1 mice, another classical SLE mouse model $(76,77)$. Cardiac cell apoptosis in NZB/W F1 mice was attenuated by $L$. paracasei (76) and hepatic cell apoptosis was ameliorated by mixture of $L$. paracasei and two different strains of $L$. reuteri (77). Several studies have shown that probiotics may have a protective effect against respiratory infections $(78,79)$, which may mitigate the potential for those autoimmune disorders caused by molecular mimicry. At the frontier of probiotic research, ghost probiotics are being investigated for their potential to protect from infections associated with autoimmune disorders $(10,11)$.

One role of probiotics in dampening autoimmunity is through enhancing gut barrier function. Leaky gut, a condition characterized by a disrupted epithelial layer, is caused by loosening of the tight junction proteins that hold a contiguous barrier in the gastrointestinal tract, and results in penetration of foreign antigens and harmful substances (80). This condition can arise from diet and stress induced dysbiotic conditions and excessive inflammation $(81,82)$. In autoimmune disease, a leaky gut can be either etiological or aggravating (80), and is characteristic in mouse models and humans with autoimmune disease $(61,83)$. Pathobionts like E. gallinarum translocate into non-gut tissues under leaky gut conditions and exacerbate disease in a lupus mouse model (NZWxBXSB) (83). We have previously shown that Lactobacillus species can effectively improve the intestinal barrier of a different strain of lupus-prone mice, MRL/lpr (61). The capacity for probiotics, prebiotics, and metabolites to enhance gut epithelial barrier function is an indication for their effectiveness in treating autoimmune diseases $(61,70)$.

Probiotics have been shown to be beneficial in a number of autoimmune diseases. In SLE, the ratio of Th17 to Treg cells is increased (84), but can be restored by probiotic mixture of Lactobacillus species (61). In a clinical trial, treatment with L. casei significantly decreased TNF- $\alpha$ and IL-10 in patients with RA (85). Although IL-12 significantly decreased in both the control and probiotic group, the ratio of IL-10 to IL12 at the end of the study was significantly higher in the probiotic group (85). The clinical course of MS is improved by shifting a Th1 response to Th2 and, among drugs such as glatiramer acetate, probiotics also have the potential for this particular immunomodulation (86). For example, a phase I clinical trial using probiotic helminths has shown increases in IL-4 and IL-10, Th2 signature cytokines (87). Experimental models of MS also showed promising immunomodulatory effects of a mixture of probiotics called IRT5 ( $L$. casei, $L$. acidophilus, L. reuteri, B. bifidum, Streptococcus thermophiles) by balancing Treg to the effector Th1 and Th17 cells (88). Early probiotics have also been associated with protection against type 1 diabetes islet autoimmunity in an international longitudinal observational study on children at risk (89). Based on these evidences, probiotics may serve as a means of correcting the effects of autoimmune-related dysbiosis and promoting the health of patients suffering from autoimmune disorders or diseases. However, there is little research investigating the impact of maternally administered probiotics on the development of autoimmunity in mothers and infants.

\section{MATERNAL PROBIOTICS \\ Pregnancy Induces Changes in Gut Microbiota}

The normal microbiota undergoes changes during pregnancy including increases in oral presence of Porphyromonas gingivalis, Aggregatibacter actinomycetemcomitans, and Candida; anaerobic and aerobic bacteria increase in the placenta; the gastrointestinal tract increases in Actinobacteria, Proteobacteria, and decreases in Faecalibacterium; and the vaginal microbiota increases in Lactobacillus species that gradually decline in presence postpartum $(90,91)$. Beta-diversity, the differences in microbial composition between samples, increases in the third trimester compared to the first trimester $(90,92)$. Streptococcus, Lactobacillus, and Enterococcus are enriched during the third trimester, and Streptococcus abundance is still enhanced 1 month postpartum, but the abundance of Faecalibacterium, which produces butyrate and promotes an anti-inflammatory environment, is reduced (90). Proteobacteria are associated with increased inflammation and transferring the human gut microbiota of the first and third trimester to germ-free mice induced a higher inflammatory response (increases in IFN $-\gamma$, IL-2, IL-6, and TNF- $\alpha$ ) in mice receiving the third trimester gut microbiota (90). Studies in German Shepherd dogs revealed that bacterial communities shift after giving birth; Fusobacteriae and Bacteroidetes decreased while Firmicutes, especially Lactobacillaceae increased (93). It has been suggested that gut microbes have the potential to colonize the vagina or spread by translocation across the epithelium into the blood stream, and this dissemination has the potential to impact pregnancy outcomes (94).

Several probiotics for maternity have appeared on the market while the research on the effect of probiotics on maternity and infants remains slim. How maternal probiotics modulate changes to the gut microbiota that occur during pregnancy must be studied. Probiotics do not, however, significantly alter the vaginal microbiota during pregnancy (95). Neither do they have a significant impact on glycemia or health of offspring in obese pregnancy (96), however a more comprehensive study including a longer probiotic administration period promises to be more revealing (97). Also, the addition of dietary counseling to probiotic consumption of Lactobacillus rhamnosus and Bifidobacterium lactis in pregnant women with metabolic disorder decreased fasting blood glucose, improved glucose tolerance, and decreased the frequency of gestational diabetes mellitus $(98,99)$. Although probiotics have been proposed to enhance the integrity of the gut epithelium barrier, studies in overweight pregnant women revealed that probiotics consisting of Bifidobacterium animals ssp lactis and Lactobacillus rhamnosus failed to reduce the increases in levels of serum zonulin and lipopolysaccharide (LPS) associated with pregnancy (100), 
both of which suggest impaired intestinal barrier function. Furthermore, infection is an important factor in pre-term labor and pathogenic microbes can be outcompeted by probiotics, yet, according to a systematic review by Jarde et al. (101) probiotics neither increased nor decreased pre-term birth (101). Kriss et al. (102) corroborates this conclusion, but suggests that high probiotic yogurt consumption may be associated with reduction in preterm delivery in Mexican women of normal weight as opposed to overweight (102). Altogether, limited evidence exists that maternal probiotics beneficially impact the mother-infant interface and more research is needed on how changes in the gut microbiota that occur during pregnancy might be modulated by probiotic treatment.

\section{The Immune System During Pregnancy}

The immune system undergoes hormone related changes during pregnancy to support and tolerate the developing fetus. Prior to our current understanding, it was believed that the mother's immune system was inactivated (103). In the 1980's it was believed that the overwhelming immune environment of the uterus was anti-inflammatory, or resembling a Th2 (high IL4 and IL-10) response. However, current research testifies to a coordinated pro- and anti-inflammatory response. Characteristic phases mark the progression of pregnancy, starting with an inflammatory phase during implantation with high levels of the cytokines IL-6, IL- 8 , and TNF- $\alpha(103,104)$. This proinflammatory state is critical for the blastocyst to rupture the uterus epithelial layer and for subsequent tissue repair (103, 104). The second phase is predominantly anti-inflammatory with markedly higher immune tolerance to facilitate rapid growth of the fetus $(103,104)$. In the third and final stage, pro-inflammatory immune responses are part of promoting contraction and rejection of the placenta $(103,104)$.

The composition of the uterine immune system during normal pregnancy is dominated by uterine natural killer (uNK) cells which aid in trophoblast invasion of the uterus (104-106) and are tolerogenic in the uterus and pro-fetus, supposedly due to a high presence of IL-10 (106). However, when these cells are relocated to non-fetal environment they resume their cytotoxic function (106). uNK cells expresses the surface marker phenotype of cytokine-producing NK cells $\left(\mathrm{CD} 56^{\text {high }} \mathrm{CD} 16^{-}\right)$, but are similar to cytotoxic $\mathrm{NK}$ cells $\left(\mathrm{CD} 56^{\text {low } /-} \mathrm{CD} 16^{+}\right)$and differ from cytokine-producing NK cells circulating in the blood due to the presence of granules (107). In 2005, NK and NKT cells were proposed to fall into different subsets based on Th1- and Th2- like cytokine profiles (108). The NK1/NKT1 subtype produces IFN- $\gamma$ and the NK2/NKT2 subtype produces IL-5 and IL-13. Furthermore, studies differentiating these subtypes showed decreases in the ratio between NK1/NKT1 and NK2/NKT2 cells were associated with healthy pregnancy (109).

Macrophages are the most abundant antigen presenting cell (APC) type, and, next to NK cells, they are the second most abundant leukocytes (105). Uterine macrophages are similar to M2 macrophages, meaning their phenotype is selective for tissue repair and is highly associated with a classical Th2 response and, like uterine DCs (uDCs), express IL-10, TGF- $\beta$, and indolamine 2,3-dioxygenase (IDO) (106). However, unlike M2 macrophages, uterine macrophages are not induced by Th2 cytokines but by macrophage colony-stimulating factor (M-CSF) and IL-10 (107). Uterine macrophages, uNK, and uDCs all play a key role in decidual formation (104). Uterine macrophages and uNK cells also facilitate remodeling of vasculature, especially spiral arteries, transient arteries that supply blood to the endometrium and decidua, through expression of molecular compounds important for angiogenesis $(107,110)$.

In regard to the adaptive immune system, $\mathrm{CD} 8^{+} \mathrm{T}$ cells are more abundant in the pregnant uterus than $\mathrm{CD} 4^{+} \mathrm{T}$ cells (105). However, the populations of helper $\mathrm{CD} 4^{+} \mathrm{T}$ cells undergo dynamic modulation during pregnancy (105). For one, a Th2like immune profile dominates over Th1, and, in fact, overexpression of the cytokines associated with Th1, IFN- $\gamma$ and IL-2, leads to spontaneous abortion (105). Levels of Th17 cells rise in the decidua and peripheral blood during the first trimester, and, by the third trimester, fall back to normal levels (111). While an unbalanced Th17 response is associated with pathological conditions including autoimmune diseases, increases in Th17 cells during early pregnancy may be necessary for the events that take place at this time, like the invasion of trophoblasts $(105,111,112) . C D 4^{+} \mathrm{CD} 25^{+}$Treg cells also increase during the first trimester, but unlike their Th17 cousins, Treg levels peak during the second trimester in the decidua and peripheral blood $(105,111,112)$. Treg cells stimulate uDCs to express IDO, which inhibits $\mathrm{T}$ cell proliferation and is also expressed in trophoblasts and macrophages (113). The mechanism of IDO activity is by catalyzing the conversion of tryptophan to kynurenine, an agonist for aryl hydrocarbon receptor (AhR) $(114,115)$. AhR has been reported to have immunosuppressive and immunemodulatory activity through the induction of TGF- $\beta$, IL-10, and IL-22 $(114,116)$.

Our knowledge is limited on how maternally administered probiotics interact in an immunomodulatory way with pregnancy-associated changes to the immune system. However, the probiotic bacterium Lactobacillus reuteri can catabolize tryptophan to indole-3-aldehyde (IAld) under high tryptophan conditions when sugars are depleted as an energy source, and, like kynurenine, IAld is another agonist of AhR $(114,115)$. Probiotics may therefore be able to enhance the immunosuppressive environment of the uterus either through direct colonization of the placenta and amniotic fluid, or by a peripheral interaction. The mechanisms by which bacteria affect the prenatal environment are further discussed in following sections. Of the few clinical studies in this area, Rautava et al. (117) found that expression of TLR1, TLR7, and MD-2, a surface protein that associates with TLR4 to confer a signaling response to LPS, were decreased in the placenta of mothers receiving $B$. lactis, but TLR3 expression increased. A combination of B. lactis and LGG decreased the transcript levels of TLR1, MD-2, and TIR domain-containing adaptor protein (TIRAP), an adaptor protein that connects TLR4 and TLR2 with MyD88 (117). Furthermore, post-delivery treatment with fermented milk with L. casei DN11201 increased NK cell levels in the blood and, only at 10 days postpartum, increased IgG4 levels, but the treatment failed to significantly alter the numbers of $\mathrm{T}$ and $\mathrm{B}$ lymphocytes 
as well as the ratio of Th1 to Th2 cells and related cytokine levels (118). At 45 days postpartum, breastmilk had significantly increased levels of IL-10 and TNF- $\alpha$ in the group receiving fermented milk, but levels of TGF- $\beta$, IL-1, IL-6, IL-8, IL-12, and IgA were unchanged (118). However, VSL\#3-a mixture of Lactobacillus, Bifidobacterium, and one Streptococcus species significantly reduced the decrease of Th2-like cytokines, IL-4 and IL-10 (95). In summary, the tolerogenic properties of probiotics may enhance the tolerogenic maternal state, but it is unclear whether they inhibit the necessary pro-inflammatory stages of pregnancy.

\section{Pregnancy and Autoimmunity}

Pregnancy is a contentious topic when it comes to autoimmune disease, especially since many autoimmune diseases, include SLE, RA, and systemic scleroderma, are female-biased (119, 120). These three aforementioned autoimmune diseases are particularly involved with pathogenesis of various kinds of kidney disease, and the kidney is a particularly vulnerable organ during the stress of pregnancy (119). The current recommendation for women with autoimmune disease is to avoid pregnancy, especially in the case of kidney disease, because it may lead to infertility and complications for the pregnant woman and her child (121-126). However, recent evidence shows that serum creatinine and glomerular filtration rate were significantly improved in pregnant patients with lupus nephritis compared to non-pregnant lupus nephritis patients (127). Pregnancy also failed to significantly exacerbate renal flares compared to control patients in lupus nephritis patients (127). Furthermore, pregnancy has been found to dampen symptoms of autoimmune diseases, such as SLE and MS, that are pathologically dependent on imbalanced Th1 and Th17 responses (113). Thus, there is conflicting evidence on how pregnancy impacts autoimmune disease and the current recommendation for women with autoimmune disease is to avoid pregnancy.

While we know that both pregnancy and probiotics may dampen autoimmune disease, the interaction between probiotics and pregnancy in autoimmune disease is poorly understood. It is therefore critical that we seek to understand how the autoimmune ameliorative effects of probiotics impact pregnancies associated with autoimmune disorders.

\section{EFFECT OF MATERNAL PROBIOTICS ON OFFSPRING}

\section{Neonatal Development of the Gut Microbiota}

The fetus, formerly believed to be sterile, was found to be colonized by bacteria via the placenta and amniotic fluid through groundbreaking research conducted in the early 2010's (128, 129). Up until this point, it was believed that infants' microbiota began with bacteria from their mothers' vaginal canal (130). The discovery that smashed the sterile womb hypothesis was followed by several ideas on how early colonization of the fetal gastrointestinal tract may occur including swallowing amniotic fluid (131), or translocation from a pregnant mothers' gastrointestinal tract to the mesenteric lymph nodes (MLN) and to the mammary glands by phagocytic immune cells (132). Similarities in bacterial load were found between infant feces and the feces, milk, and blood of the mom (132). Supporting this hypothesis, the bacterial load of MLNs in mice was determined to be higher during late pregnancy followed by a steep decline after birth, concomitant with a sharp increase of bacteria present in mammary tissue during lactation (132). Additionally, hormonal changes may increase permeability of the gut epithelium during pregnancy and lactation, further facilitating transfer of bacteria from the gut to the mammary tissue (133). Two studies support a transfer system from the gut to the mammary gland: one showed genetically labeled Enterococcus faecium in the meconium of pups born to mice orally gavaged with the bacteria (134), and the other, a more recent study, traced the tissues that fluorescently labeled Lactobacillus lactis and L. salivarius translocated to when administered via gavage to pregnant $\mathrm{BALB} / \mathrm{c}$ mice (135). Are these translocated bacteria artifacts of active phagocytic cells or is there an alternative mechanism of transport? While this question remains unanswered, some evidence contradicts the hypothesis of translocation from the gut through the MLN to the mammary glands. For example, Treven et al. (35) conducted a study in which pregnant mice gavaged with $4 \times 10^{8}$ colony forming units (cfu) per dose of either LGG or Lactobacillus gasseri K7 (LK7) were sacrificed at 3 and 8 days postpartum. Bacteria from the MLN and mammary gland were assessed. Neither LGG nor LK7 were found in the probiotic treated MLN or mammary gland, yet bacteria from the genus Lactobacilliceae were only present in the mammary gland of probiotic treated mice (35). Similarly, treatment of women with VLS\#3 during pregnancy showed that the probiotic organisms administered did not enter the mammary gland, but the probiotic group had higher numbers of Lactobacilli and Bifidobacteria detected in the colostrum of milk (136). However, this contradiction may be explained if translocation is a transient phenomenon, as Perez reported his findings from 1 day postpartum and Treven et al. (35) reported his findings from 3 to 8 days postpartum. In summary, there is evidence that infants receive their microbiota, both through prenatal exposure and through nursing, from the bacteria that colonize the mother's gastrointestinal tract (Figure 1). However, the evidence is not conclusive. As previously mentioned, probiotics were also found to alter the vaginal microbiota, and, therefore, influence the development of the infant's gut microbiota.

With this in mind, literature also supports that the gut microbiota of vaginally delivered newborns are closer in resemblance to the mother's vaginal microbiota than her gut, and newborns delivered by Cesarean section have a microbiota most similar to the skin microbiota $(130,137)$. In general, the microbiota of an infant lacks the diversity of an adult (93), and the infant's microbiota is most similar to their mother's microbiota at 4 years old (90). It does not reach full diversity until after 4 years of age (138). One study showed the probiotic L. casei subsp. rhamnosus administered to infants from birth to 6 months greatly altered the gut microbiota, significantly increasing 682 taxa including other lactic acid bacterial species 


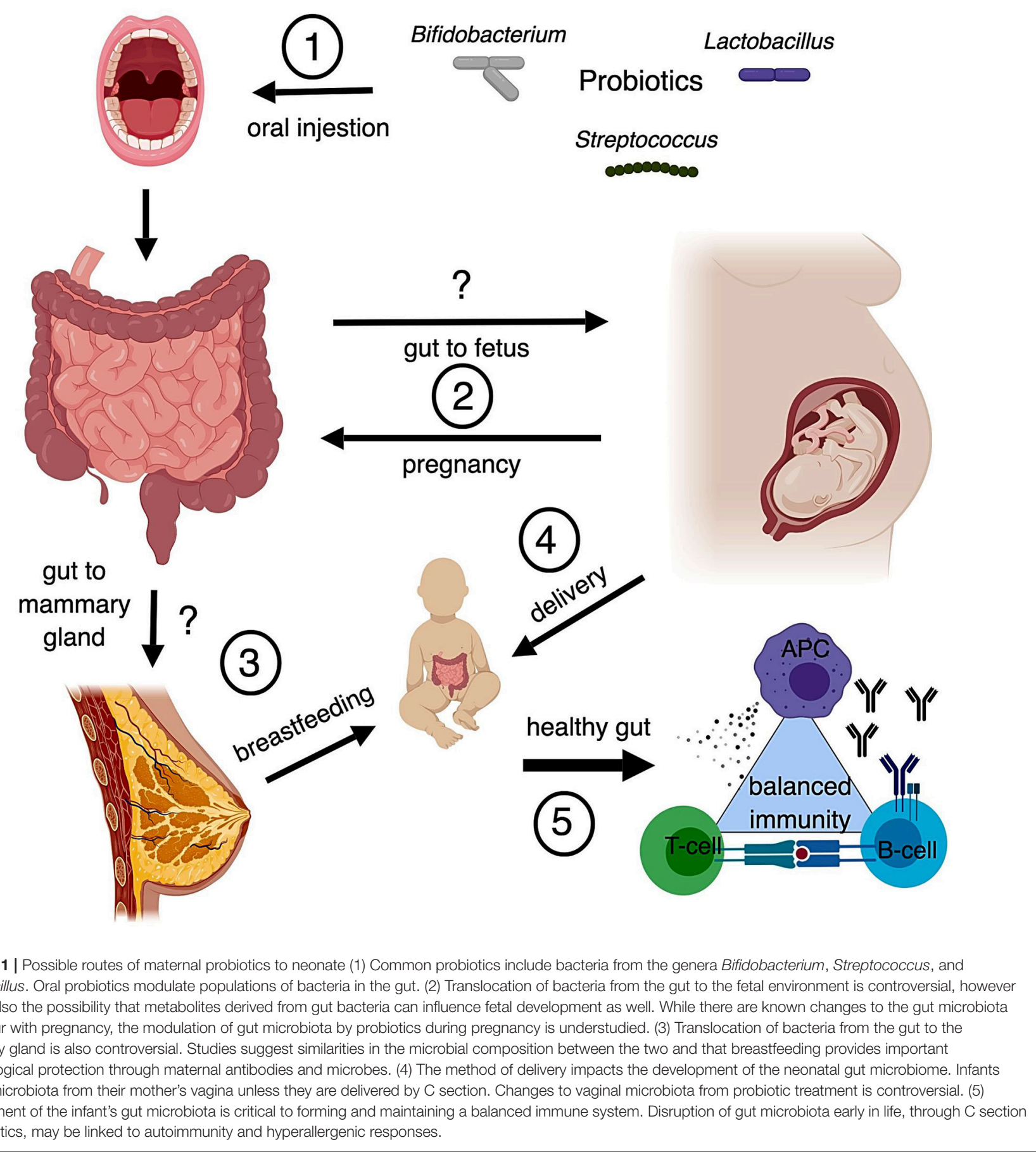

(139). Proteobacteria represented $60 \%$ of the taxa that were significantly increased (139). Another study on the long-term effects of probiotics on atopic children showed that probiotics did not significantly alter the diversity of bacterial phyla and that the gut microbiota is most unstable during the first two years of life with rather dramatic fluctuation in major phyla (140). Also, there was no long-term effect of probiotic treatment on the composition of the gut microbiota (140). However, probiotics did result in the removal of Lactococcus from the probiotic treated group during intervention (140). Another study showed similar results, the composition of the gut microbiota changed dramatically over time but retained a notable number of bacterial species from birth to 3 years of age (141). Also, the functional metabolic pathways remained static even though the bacterial communities changed (141). Other studies, such as a placebocontrolled study in Finland and Germany, found that treating mothers with probiotics during lactation significantly altered populations of bacteria, specifically L. rhamnosus and B. longum 
given to Finnish women was reflected in the offspring by higher percentages of Lactobacillus and Enterococcus and lower levels of Bifidobacterium (142). Interestingly, the effects varied between the two countries due to differences in the way that infants were fed and seeding microbiota (142). In mice, the colonic gut microbiota was examined with treatment of probiotic fermented milk with $L$. casei DN-114001 (143). This study included four groups: no treatment, only pups received probiotics, only dams received probiotics, and both dams and pups received probiotics (143). Bifidobacteria and Enterobacteria levels were significantly increased in both groups where probiotics were fed to dams (143). After weaning, groups that did not feed probiotics to the pups saw a decline in Bifidobacteria and Enterobacteria levels (143). Similarly, maternal treatment with Clostridium butyricum increased levels of Lactobacillus and Bifidobacterium in pups while decreasing levels of Enterobacter spp (144). However, after weaning, the group giving C. butyricum only to pups overtook all other groups in the levels of Bifidobacterium and Lactobacillus (144). In all, the infant gut microbiota may be more susceptible to changes in structure, but not function, than the adult gut, and therefore easily influenced by probiotic intervention.

The health implications for either maternally administered or early childhood probiotics are diverse. L. rhamnosus when administered at $10^{10}$ cfu every day for 4 weeks before birth and then continued for 6 months either to breastfeeding mothers or in water given to offspring moderated excessive weight gain in offspring (145). Furthermore, one of the most significant advances in infant probiotic therapy is the mounting evidence that they can reduce the incidence of necrotizing enterocolitis in pre-term infants $(131,146)$. Besides development of a robust immune system, the infant gut microbiota is critical for angiogenesis in the gastrointestinal system and pre-term infants have a severely deficient microbiota infants $(131,146)$. Necrotizing enterocolitis is a condition in which the vasculature of the gastrointestinal tract is not well developed, as occurs in pre-term infants, and results in the death of gut tissue infants $(131,146)$. Studies in germ-free mice show that development of vasculature can be induced by colonizing the gut with normal microbiota, and that the gut epithelium is an important mediator between the microbiota and vasculature (147). Thus, the use of early probiotic intervention has made significant advances in developmental healthcare strategies, with the caveat that perinatal probiotic exposure can alter off-target developmental processes (148).

\section{Modulation of the Developing Immune System}

At birth, the immune system is naïve and the adaptive immune system is undeveloped. Specific differences exist in a neonatal innate immune system compared to an adult (149). Similar to the uterine environment, newborns have a higher number of NK cells than adults, and the NK cells are deficient in cytotoxic capacities, much like uNK cells (149). Neonatal blood contains more monocytes but less plasmacytoid DCs (pDCs) than adults (150). Additionally, neonatal whole blood monocytes, conventional DCs (cDCs), and pDCs are less responsive and less polyfunctional than their adult counterparts. Interestingly, these differences are most profound following TLR1/2, TLR4, and TLR7/8 stimulation and, for the monocytes and cDCs, only observed in umbilical cord whole blood-a proxy for neonatal blood-instead of PBMC isolated cells (150). This indicates a role for soluble factors that suppressed the responsiveness (151). In general, neonatal immune cells produced less type 1 cytokines, more Th17-inducing cytokines, and more IL-10 (150). As for the adaptive immune system, like the uterine environment, Th1 cytokines such as IFN- $\gamma$ are reduced (152). Studies in rats showed that germinal centers in the spleen, lymph nodes, and Peyer's patches didn't develop until after 20 days of age, which is between the times when rats are weaned and reach sexual maturity (153). Interestingly, nascent follicles begin to form around seven days of age, which is about 5 days before rats begin to nibble on solid food (153). The beginning of eating a non-maternally supplemented diet marks the maturation of the immune system adaptive compartments and the end of provisional protection from a mother's milk. Prior to maturation, maternal antibodies are transferred to infants through milk and constitute early adaptive immunity (154). Specifically, IgA is the main antibody produced by the mucosal associated lymphoid tissue (MALT) of the mammary glands (154). IgA crosses the epithelium by binding to polymeric immunoglobulin receptor (pIgR) on the basal side of epithelial cells and transcytosis into the milk ducts (154). Early endogenous mucosal IgA production can be stimulated earlier in the absence of maternally transferred antibodies, such as the case when immunocompetent mice nurse on immunocompromised mothers (155). In this scenario, it is still unknown whether or not there is an immune stimulatory factor in milk that enhances early endogenous IgA production. However, it is known that the maternally transferred microbiota are responsible for jumpstarting the immune system (156). Translocation of bacteria from the gut to the MLN, where antigens from the bacteria are presented to educate adaptive immune cells, occurs spontaneously in infants during the nursing period (157). Therefore, the gut microbiota is important for education and maturation of the immune system.

Perinatal probiotics can shape the development of the immune system. Maternally administered B. lactis reduced TLR7 mRNA expression in the fetal intestines, whereas a combination of LGG and B. lactis decreased TLR6 mRNA expression (117). Postnatal probiotic supplemented food given to lactating mice significantly increased their offspring's Treg cell populations in saline control and peanut extract induced allergic response groups, but did not change inducible Treg cell populations (158). Probiotic treatment also decreased IL-6, IL-9, TNF- $\alpha$, IL-17, and IL-7 mRNA expression in the pups' spleens (158). When probiotic fermented milk containing L. casei DN-114001 was administered to dams, the offspring had in increased level of secretory IgA in intestinal luminal fluid at 12 days of age, however at 28 days of age the same pups had a lower number of cells producing IgA in the small intestines (143). Additionally, when dams were fed probiotics their offspring had decreased numbers of macrophages at 12 days of age, but when probiotics were administered to postnatally the number of mature F4/80 macrophages was significantly increased by 45 days of age (143). 
Contrary to these findings, C. butyricum treatment in either dams or pups, although it similarly increased levels of Bifidobacterium, did not significantly affect the levels of secretory IgA in intestinal fluid at 14 and 28 days of age (144). Probiotic milk containing a combination of $5 \times 10^{10} \mathrm{cfu} L$. rhamnosus, $5 \times 10^{10} \mathrm{cfu} B$. animalis, and $5 \times 10^{8} \mathrm{cfu}$ L. acidophilus per dose administered daily during pregnancy conferred a decreased risk of atopic dermatitis in infants and a decrease in the proportion Th22 cells, however no difference in other Thelper cell subsets or Th1 to Th2 ratio was observed (159). B. pseudocatenulatum administered 2 days postnatally to $\mathrm{C} 57 \mathrm{BL} / 6$ mice until 21 days old decreased stress hormones in a model for gut-brain involvement in early life trauma and chronic stress induced by maternal separation (160). The probiotic treatment also dampened LPS induced IFN- $\gamma$ expression in MLN cells, which attributed to increased sensitivity to glucocorticoids (160). Altogether, probiotics received perinatally encourage endogenous adaptive immune response, enhance immune system maturation, and reduce pro-inflammatory immune responses. Yet, these results are still controversial and many discrepancies exist.

\section{Influence of Maternal Probiotics on Autoimmunity in Offspring}

While maternal probiotics have attracted attention for the health of newborns by reducing allergies and incidence of pre-eclampsia (161, 162), only one study has been has been reported on perinatal probiotics for autoimmune disease. This study found no association between incidence of celiac disease in children and maternally administered probiotics during late pregnancy and nursing (163). Although there is scant evidence for maternal probiotic intervention for autoimmune disease in infants, there is evidence that early microbial associated disruptions may be a contributing factor to the development of autoimmune disease. In children who develop type 1 diabetes, a decrease in the diversity of the gut microbiota occurs after seroconversion and before diagnosis (141). The bacterial genera Blautia and Ruminococcus were found in higher abundance in children who developed type 1 diabetes and contributed to increased serum levels of branched-chain amino acids (141). Furthermore, the genetic expression of the microbiota changes before the onset of clinical symptoms, and these changes include increases in sugar transport systems (141). Also, children born by Csection or exposed to prenatal antibiotics had increased risk of celiac disease, asthma and type 1 diabetes (164). Thus, evidence supports the importance of maternal transfer of the gut microbiota in prevention of autoimmune disease and creates a gap that could potentially be filled by probiotics intervention.

\section{REFERENCES}

1. Arora T, Singh S, Sharma RK. Probiotics: interaction with gut microbiome and antiobesity potential. Nutrition (2013) 29:591-6. doi: 10.1016/j.nut.2012.07.017

2. Gao Z, Guo B, Gao R, Zhu Q, Wu W, Qin H. Probiotics modify human intestinal mucosa-associated microbiota in patients with colorectal cancer. Mol Med Rep. (2015) 12:6119-27. doi: 10.3892/mmr.2015.4124

\section{CONCLUSIONS}

Significant grounds have been covered in establishing the link between dysbiosis and autoimmune disease marked by the presence of a leaky gut and systemic inflammation. From what we can study of the complex ecosystem that is the gut microbiota, probiotics induce significant changes to the normal microbiota and enhance anti-inflammatory immune reactions. Through their immunological modulatory capacity, probiotics can therefore alleviate autoimmune disease severity.

The normal gut microenvironment undergoes specific changes during maternity including an increase in gut barrier permeability. Furthermore, specific changes in the immune system occur to support and tolerate the developing fetus. Maternally administered probiotics may impact the health of a child by altering the bacteria that initially colonize the developing infant. Maternal probiotics thus have the potential to influence neonatal immune development since the initial programming of the immune system is dependent on the gut microbiota.

As the influence of the maternal-neonatal interface on the gut microbiota in autoimmune disease is a poorly understood, further research is required regarding the impact of maternal probiotics on the development of the fetus and the implications in autoimmune disease. A number of gaps exist in the literature regarding maternal probiotics for autoimmune diseases in both mothers and their children. Designing studies aimed at understanding how probiotics act in an immunomodulatory capacity to ameliorate or exacerbate autoimmune diseases in pregnancy and infancy is, without excuse, a requisite edge for cutting into the issues surrounding autoimmunity and pregnancy.

\section{AUTHOR CONTRIBUTIONS}

BS: research, writing, editing, figure design; XL: research, editing.

\section{FUNDING}

Preparation of this publication was supported by the National Institute of Arthritis and Musculoskeletal and Skin Diseases of the National Institutes of Health under Award Number 1R01AR073240 and 1R15AR067418. The content is solely the responsibility of the authors and does not necessarily represent the official views of the National Institutes of Health.
3. Singh RK, Chang H-W, Yan D, Lee KM, Ucmak D, Wong K, et al. Influence of diet on the gut microbiome and implications for human health. J Transl Med. (2017) 15:73. doi: 10.1186/s12967-017-1175-y

4. Vitetta L, Coulson S, Linnane AW, Butt H. The gastrointestinal microbiome and musculoskeletal diseases: a beneficial role for probiotics and prebiotics. Pathogens (2013) 2:606-26. doi: 10.3390/pathogens2040606

5. Reardon S. Microbiome therapy gains market traction. Nature (2014) 509:269-70. doi: 10.1038/509269a 
6. Guarnera F, Schaafsmab G. Probiotics. Int J Food Microbiol. (1998) 39:237-8.

7. Hotel A, Cordoba A. Health and Nutrition Properties of Probiotics in Food Including Powder Milk With Live Lactic Acid Bacteria. Antergia: FAO/WHO (2001). p. 1-34.

8. Hill C, Guarner F, Reid G, Gibson GR, Merenstein DJ, Pot B, et al. Expert consensus document: the international scientific association for probiotics and prebiotics consensus statement on the scope and appropriate use of the term probiotic. NatRev Gastroenterol Hepatol. (2014) 11:506-14. doi: 10.1038/nrgastro.2014.66

9. Bermudez-Brito M, Plaza-Dia J, Munoz-Quezada S, Gomez-Llorente C, Gil A. Probiotic mechanisms of action. Ann Nutr Metab. (2012) 61:160-74. doi: $10.1159 / 000342079$

10. Bajpai V, Chandra V, Kim N, Rai R, Kumar P, Kim K. Ghost probiotics with a combined regimen: a novel therapeutic approach against the Zika virus, an emerging world threat. Crit Rev Biotechnol. (2018) 38:438-54. doi: 10.1080/07388551.2017.13 68445

11. Taverniti V, Guglielmetti S. The immunomodulatory properties of probiotic microorganisms beyond their viability (ghost probiotics: proposal of paraprobiotic concept). Genes Nutr. (2011) 6:261-74. doi: 10.1007/s12263-011-0218-x

12. Gaspar C, Donders G, Palmeira-de-Oliveira R, Queiroz J, Tomaz C, Martinez-de-Oliveira J, et al. Bacteriocin production of the probiotic Lactobacillus acidophilus KS400. AMB Express. (2018) 8:153. doi: 10.1186/s13568-018-0679-z

13. Benson K, Redman K, Carter S, Keller D, Farmer S, Endres J, et al. Probiotic metabolites from Bacillus coagulans GanedenBC30 ${ }^{\mathrm{TM}}$ support maturation of antigen-presenting cells in vitro. World J Gastroenterol. (2012) 18:1875-83. doi: 10.3748/wjg.v18.i16.1875

14. Haase S, Haghikia A, Wilck N, Muller D, Linker R. Impacts of microbiome metabolites on immune regulation and autoimmunity. Immunology (2018) 154:230-8. doi: 10.1111/imm.12933

15. Kumar M, Nagpal R, Verma V, Kumar A, Kaur N, Hemalatha R, et al. Probiotic metabolites as epigenetic targets in the prevention of colon cancer. Nutr Rev. (2013) 171:23-34. doi: 10.1111/j.1753-4887.2012. 00542.x

16. Ye J, Lv L, Wu W, Li Y, Shi D, Fang D, et al. Butyrate protects mice against methionine-choline-deficient diet-induced non-alcoholic steatohepatitis by improving gut barrier function, attenuating inflammation and reducing endotoxin levels. Front Microbiol. (2018) 9:1967. doi: 10.3389/fmicb.2018. 01967.eCollection2018

17. Ashraf R, Vasilijevic T, Smith S, Donkor O. Effect of cell-surface components and metabolites of lactic acid bacteria and probiotic organisms on cytokine production and induction of CD25 expression in human peripheral mononuclear cells. J Dairy Sci. (2014) 97:2542-58. doi: $10.3168 /$ jds.2013-7459

18. McKenzie C, Tan J, Macia L, Mackay C. The nutrition-gut microbiomephysiology axis and allergic diseases. Immunol Rev. (2017) 278:277-95. doi: 10.1111/imr.12556

19. Thienhaus O. Dogs as Probiotics. (2015). Available online at: https:// clinicaltrials.gov/ct2/show/NCT02343731?term=probiotic+dogsandrank=1

20. Iiyuefeng S. The Efficacy of Mechanisms of Oral Probiotics in Preventing Necrotizing Enterocolitis. (2015). Available online at: https://clinicaltrials. gov/ct2/show/NCT02552706?term=probioticsandcond=necrotizing+ enterocolitisandrank $=3$

21. Milev R. Effects of Probiotics on Symptoms of Depression (EPSD). (2018). Available online at: https://clinicaltrials.gov/ct2/show/NCT03277586?term= probioticsandcond=anxiety+and+depressionandrank $=2$

22. Szajewska H. Probiotics in Newly Recognized Type 1 Diabetes. (2017). Available online at: https://clinicaltrials.gov/ct2/show/NCT03032354?term= probioticsandcond=Autoimmuneandrank $=1$

23. Shenzhen People's Hospital. Effect of Live Combined Bifidobacterium and Lactobacillus on Glycemic Control and Other Outcomes in Type 1 Diabetes. (2018). Available online at: https://clinicaltrials.gov/ct2/show/ NCT03556631?term=probioticsandcond=Autoimmuneandrank=2

24. Smerud K. Probiotics in IgA Nephropathy. (2013). Available online at: https:// clinicaltrials.gov/ct2/show/NCT01781312?term=probioticsandcond= Autoimmuneandrank $=3$
25. Hillman ET, Lu H, Yao T, Nakatsu CH. Microbial ecology along the gastrointestinal tract. Microbes Env. (1977) 32:300-13. doi: 10.1264/jsme2.ME17017

26. Jandhyala SM, Talukdar R, Subramanyam C, Vuyyuru H, Sasikala M, Reddy DN. Role of the normal gut microbiota. World J Gastroenterol. (2015) 21:8787-803. doi: 10.3748/wjg.v21.i29.8787

27. De Vos P, Garrity GM, Jones D, Krieg NR, Ludwig W, Rainey FA, et al. Bergey's Manual of Systematic Bacteriology. New York, NY: Springer (2009)

28. Bergey D, Boone DR, Garrity GM, Staley JT. Bergey's Manual of Systematic Bacteriology. New York, NY: Springer (2010)

29. Swidsinski A, Loening-Baucke V, Lochs H, Hale LP. Spatial organization of bacterial flora in normal and inflamed intestine: a fluorescence in situ hybridization study in mice. World J Gastroenterol. (2005) 11:1131-40. doi: 10.3748/wjg.v11.i8.1131

30. Herstad K, Moen A, Gaby J, Moe L, Skancke E. Characterization of the fecal and mucosa-associated microbiota in dogs with colorectal epithelial tumors. PLoS ONE (2018) 13:e0198342. doi: 10.1371/journal.pone.0198342

31. Mann E, Schmitz-Esser S, Zebeli Q, Wagner M, Ritzmann M, Metzler-Zebeli BU. Mucosa-associated bacterial microbiome of the gastrointestinal tract of weaned pigs and dynamics linked to dietary calcium-phosphorus. PLOS ONE (2014) 9:e86950. doi: 10.1371/journal.pone.0086950

32. Odamaki T, Kato K, Sugahara H, Xiao J, Abe F, Benno Y. Effect of probiotic yoghurt on animal-based diet-induced change in gut microbiota: an open, randomised, parallel-group study. Benef Microbes. (2016) 7:473-84. doi: 10.3920/BM2015.0173

33. Degirolamo C, Rainaldi S, Bovenga F, Murzilli S, Moschetta A. Microbiota modification with probiotics induces hepatic bile acid synthesis via downregulation of the Fxr-Fgf15 axis in mice. Cell Rep. (2014) 7:12-8. doi: 10.1016/j.celrep.2014.02.032

34. Jones ML, Tomaro-Duchesneau C, Prakash S. The gut microbiome, probiotics, bile acids axis, and human health. Trends Microbiol. (2014) 22:306-8. doi: 10.1016/j.tim.2014.04.010

35. Treven P, Mrak V, Bogovic Matijasic B, Horvat S, Rogelj I. Administration of probiotics Lactobacillus rhamnosus GG and Lactobacillus gasseri K7 during pregnancy and lactation changes mouse mesenteric lymph nodes and mammary gland microbiota. J Dairy Sci. (2015) 98:2114-28. doi: $10.3168 /$ jds.2014-8519

36. Shadnoush M, Hosseini RS, Khalilnezhad A, Navai L, Goudarzi H, Vaezjalali M. Effects of probiotics on gut microbiota in patients with inflammatory bowel disease: a double-blind, placebo-controlled clinical trial. Kor J Gastroenterol. (2015) 65:215-21. doi: 10.4166/kjg.2015.65.4.215

37. Piano M, Carmagnola S, Ballare M, Balzarini M, Montino F, Pagliarulo M, et al. Comparison of the kinetics of intestinal colonization by associating 5 probiotic bacteria assumed either in a microencapsulated or in a traditional, uncoated form. J Clin Gastroenterol. (2012) 46(Suppl):S85-92. doi: 10.1097/MCG.0b013e3182672796

38. Severance EG, Gressitt KL, Stallings CR, Katsafanas E, Schweinfurth LA, Savage CL, et al. Probiotic normalization of Candida albicans in schizophrenia: a randomized, placebo-controlled, longitudinal pilot study. Brain Behav Immun. (2017) 62:41-5. doi: 10.1016/j.bbi.2016.11.019

39. Park D-Y, Ahn Y-T, Park S-H, Huh C-S, Yoo S-R, Yu R, et al. Supplementation of Lactobacillus curvatus HY7601 and Lactobacillus plantarum KY1032 in diet-induced obese mice is associated with gut microbial changes and reduction in obesity. PLoS ONE (2013) 8:e59470. doi: 10.1371/journal.pone.0059470

40. Pradhan B, Guha D, Naik AK, Banerjee A, Tambat S, Chawla S, et al. Probiotics L. acidophilus and B. clausii modulate gut microbiota in Th1- and Th2-biased mice to ameliorate salmonella typhimurium-induced diarrhea. Probiotics Antimicro Prot. (2018). doi: 10.1007/s12602-018-9436-5. [Epub ahead of print].

41. Bajaj JS, Heuman DM, Hylemon PB, Sanyal AJ, Puri P, Sterling RK, et al. Randomized clinical trial: lactobacillus $g g$ modulates gut microbiome, metabolome and endotoxemia in patients with cirrhosis. Aliment Pharmacol Ther. (2014) 39:1113-25. doi: 10.1111/apt.12695

42. Wang K, Yu X, Guo Y, Ge L, Pu F, Ma X, et al. Bifidobacterium bifidum TMC3115 can characteristically influence glucose and lipid profile and intestinal microbiota in the middle-aged and elderly. Probiotics Antimicro Prot. (2018). doi: 10.1007/s12602-018-9441-8. [Epub ahead of print]. 
43. Lin H, Tang C, Chen J, Chuang J, Huang S, Tan T, et al. Peptidoglycan induces interleukin-6 expression through the TLR2 receptor, JNK, cJun, and AP-1 pathways in microglia. J Cell Physiol. (2011) 226:1573-82. doi: $10.1002 /$ jcp.22489

44. Schwandner R, Dziarski R, Wesche $H$, Rothe $M$, Kirschning C. Peptidoglycan- and lipoteichoic acid-induced cell activation is mediated by toll-like receptor 2. J Biol Chem. (1999) 274:17406-9.

45. Cammarota M, De Rosa M, Stellavato A, Lamberti M, Marzaioli I, Giuliano M. In vitro evaluation of Lactobacillus plantarum DSMZ 12028 as a probiotic: emphasis on innate immunity. Int J Food Microbiol. (2009) 35:908. doi: 10.1016/j.ijfoodmicro.2009.08.022

46. Plaza-Diaz J, Gomez-Llorente C, Fontana L, Gil A. Modulation of immunity and inflammatory gene expression in the gut, in inflammatory diseases of the gut and in the liver by probiotics. Wrold J Gastroenterol. (2014) 20:15632-49. doi: 10.3748/wjg.v20.i42.15632

47. Wang Y, Xie J, Wang N, Li Y, Sun X, Zhang Y, et al. Lactobacillus casei Zhang modulate cytokine and Toll-like receptor expression and beneficially regulate poly I:C-induced immune responses in RAW264.7 macrophages. Microbiol Immunol. (2013) 57:54-62. doi: 10.1111/j.1348-0421.516.x

48. Toubiana J, Rossi A-L, Belaidouni N, Grimaldi D, Pene F, Chafey P, et al. Srcfamily-tyrosine kinase Lyn is critical for TLR2-mediated NF-kB actvation through the PI 3-kinase signaling pathway. Innate Immun. (2015) 21:685-97. doi: $10.1177 / 1753425915586075$

49. Lim S, Kim D. Bifidobacterium adolescentis IM38 ameliorates highfat diet-induced colitis in mice by inhibiting NF-kB activation and lipopolysaccharide production by gut microbiota. Nutr Res. (2017) 41:86-96. doi: 10.1016/j.nutres.2017.04.003

50. Lim S, Jang H, Jang S, Han M, Kim D. Lactobacillus fermentum IM12 attenuates inflammation in mice by inhibiting NF-kB STAT3 signalling pathway. Benef Microbes. (2017) 8:407-19. doi: 10.3920/BM2016.0156

51. Ryu S-H, Park J-H, Choi S-Y, Jeon H-Y, Park J-I, Kim J-Y, et al. The probiotic Lactobacillus prevents Citrobacter rodentium-induced murine colitis in a TLR2-dependent manner. J Microbiol Biotechnol. (2016) 26:1333-40. doi: 10.4014/jmb.1602.02004

52. Kang H-J, Im S-H. Probiotics as immune modulators. J Nutr Sci Vitaminol. (2015) 61(Suppl):S103-5. doi: 10.3177/jnsv.61.S103

53. Jain S, Yadav H, Sinha PR, Marotta F. Modulation of cytokine gene expression in spleen and Peyer's patches by feeding dahi containing probiotic Lactobacillus casei in mice. J Dig Dis. (2009) 10:49-54. doi: 10.1111/j.1751-2980.2008.00362.x

54. Ashraf R, and Shah NP. Immune system stimulation by probiotic microorganisms. Crit Rev Food Sciand Nutr. (2014) 54:938-56. doi: 10.1080/10408398.2011.619671

55. Kim H-J, Kim HY, Lee S-Y, Seo J-H, Lee E, Hong S-J. Clinical efficacy and mechanism of probiotics in allergic disease. Kor J Pediatr. (2013) 56:369-76. doi: 10.3345/kjp.2013.56.9.369

56. Kwon H-K, Lee C-G, So J-S, Chae C-S, Hwang J-S, Sahoo A, et al. Generation of regulatory dendritic cells and CD4+FoxP3+ T cells by probiotics administration suppresses immune disorders. Proc Natl Acad Sci USA. (2009) 107:2159-64. doi: 10.1073/pnas.090405510

57. Zhao H-M, Huang X-Y, Zuo Z-Q, Pan Q-H, Ao M-Y, Zhou F, et al. Probiotics increase $T$ regulatory cells and reduce severity of experimental colitis in mice. World J Gastroenterol. (2013) 19:742-9. doi: 10.3748/wjg.v19.i5.742

58. Zheng B, van Bergenhenegouwen J, Overbeek S, van de Kant HJ, Garssen J, Folkerts $\mathrm{G}$, et al. Bifidobacterium breve attenuates murine dextran sodium sulfate-induced colitis and increases regulatory $\mathrm{T}$ cell responses. PLoS ONE (2014) 9:e95441. doi: 10.1371/journal.pone.0095441

59. Miyao T, Floess S, Setoguchi R, Luche H, Fehling HJ, Waldermann H, et al. Plasticity of Foxp3 $+\mathrm{T}$ cells reflects promiscuous Foxp3 expression in conventional $\mathrm{T}$ cells but not reprogramming of regulatory $\mathrm{T}$ cells. Immunity (2012) 36: 262-75. doi: 10.1016/j.immuni.2011.12.012

60. Kawai K, Uchiyama M, Hester J, Wood K, Issa F. Regulatory $\mathrm{T}$ cells for tolerance. Hum Immunol. (2018) 79:294-303. doi: 10.1016/j.humimm.2017.12.013

61. Mu Q, Zhang H, Liao X, Lin K, Liu H, Edwards M, et al. Control of lupus nephritis by changes of gut microbiota. Microbiome (2017) 5:73. doi: 10.1186/s40168-017-0300-8
62. Liao H, Tao L, Zhao J, Qin J, Zeng G, Cai S, et al. Clostridium butyricum in combination with specific immunotherapy converts antigen-specific B cells to regulatory B cells in asthmatic patients. Sci Rep. (2016) 6:20481. doi: $10.1038 /$ srep20481

63. Arai S, Iwabuchi $\mathrm{N}$, Takahashi $\mathrm{S}$, Xiao J, Abe F, Hachimura S. Orally administered heat-killed Lactobacillus paracasei MCC1849 enhances antigen-specific IgA secretion and induces follicular helper T cells in mice. PLoS ONE (2018) 13:e0199018. doi: 10.1371/journal.pone.0199018

64. Kikuchi Y, Kunitoh-Asari A, Hayakawa K, Imai S, Kasuya K, Abe K, et al. Oral administration of Lactobacillus plantarum strain AYA enhances IgA secretion and provides survival protection against influenza virus infection in mice. PLoS ONE (2014) 9:e86416. doi: 10.1371/journal.pone.00 86416

65. Pollard K, Christy J, Cauvi D, Kono D. Environmental xenobiotic exposure and autoimmunity. Curr Opin Toxicol. (2018) 10:15-22. doi: 10.1016/j.cotox.2017.11.009

66. Wang L, Wang F-S, Gershwin ME. Human autoimmune diseases: a comprehensive update. J Int Med. (2015) 278:369-95. doi: 10.1111/joim.12395

67. Kuhn K, Pedraza I, Demoruelle M. Mucosal immune responses to microbiota in the development of autoimmune disease. Rheum Clin North Am. (2014) 40:711-25. doi: 10.1016/j.rdc.2014.07.013

68. Jethwa $\mathrm{H}$, Abraham S. The evidence for microbiome manipulation in inflammatory arthritis. Rheumatology (2017) 56:1452-60. doi: 10.1093/rheumatology/kew374

69. $\mathrm{Mu} \mathrm{Q}$, Zhang $\mathrm{H}$, Luo $\mathrm{X}$. SLE: another autoimmune disorder influenced by microbes and diet? Front Immunol. (2015) 6:608 doi: 10.3389/fimmu.2015.00608

70. de Oliveira G, Leite A, Higuchi B, Gonzaga M, Mariano V. Intestinal dysbiosis and probiotic applications in autoimmune disease. Immunology (2017) 152:1-12. doi: 10.1111/imm.12765

71. Opazo MC, Ortega-Rocha EM, Coroado-Arrazola I, Bonifaz LC, Boudin $\mathrm{H}$, Neunlist $\mathrm{M}$, et al. Intestinal microbiota influences nonintestinal related autoimmune diseases. Front Microbiol. (2018) 9:432. doi: 10.3389/fmicb.2018.00432

72. Esposito S, Longo MR. Guillain-Barre syndrome. Autoimmun Rev. (2016) 16:96-101. doi: 10.1016/j.autrev.2016.09.022

73. Keat A, Thomas B, Dixey J, Osborn M, Sonnex C, Taylor-Robinson D. Chlamydia trachomatis and reactive arthritis: the missing link. Lancet (1987) $1: 72-4$.

74. Lichtman S, Wang J, Sartor RB, Zhang C, Bender D, Dalldorf FG, et al. Reactivation of arthritis induced by small bowel bacterial overgrowth in rats: role of cytokines, bacteria and bacterial polymers. Infect Immun. (1995) 63:2295-301.

75. Esmaeili S, Mahmoudi M, Momtazi A, Sahebkar A, Doulabi H, Rastin M. Tolerogenic probiotics: potential immunoregulators in systemic Lupus Erythematosus. J Cell Physiol. (2017) 232:1994-2007. doi: 10.1002/jcp.25748

76. Hu W, Rajendran P, Tzang B, Yeh Y, Shen C, Chen R, et al. Lactobacillus paracasei GMNL-32 exerts a therapeutic effect on cardiac abnormalities in NZB/W F1 mice. PLoS ONE (2017) 12:e0185098. doi: 10.1371/journal.pone.0185098

77. Hsu T, Huang C, Liu C, Hsu K, Chen Y, Tzang B. Lactobacillus paracasei GMNL-32, Lactobacillus reuteri GMNL-89 and L. reuteri GMNL-263 ameliorate hepatic injuries in lupus-prone mice. Br J Nutr. (2017) 117:106674. doi: 10.1017/S000711451700103

78. Garcia-Crespo K, Chan C, Gabryszewski S, Percopo C, Rigaux P, Dyer K, et al. Lactobacillus priming of the respiratory tract: heterologous immunity and protection against lethal pneumovirus infection. Antivir Res. (2013) 97:270-9. doi: 10.1016/j.antiviral.2012.12.022

79. Percopo C, Rice T, Brenner T, Dyer K, Luo J, Kanakabandi K, et al. Immunobiotic Lactobacillus administered post-exposure averts the lethal sequelae of respiratory virus infection. Antivir Res. (2015) 121:109-19. doi: 10.1016/j.antiviral.2015.07.001

80. Fasano A, Shea-Donohue T. Mechanisms of disease: the role of intestinal barrier function in the pathogenesis of gastrointestinal autoimmune diseases. Nat Clin Pract Gastroenterol Hepato. (2005) 2:416-22. doi: 10.1038/ncpgasthep0259 
81. De Santis S, Cavalcanti E, Mastronardi M, Jirillo E, Chieppa M. Nutritional keys for intestinal barrier modulation. Front Immunol. (2015) 6:612. doi: 10.3389/fimmu.2015.00612

82. Lam Y, Ha C, Campbell C, Mitchell A, Dinudom A, Oscarsson J, et al. Increased gut permeability and microbiota change associate with mesenteric fat inflammation and metabolic dysfunction in diet-induced obese mice. PLoS ONE (2012) 7:e34233. doi: 10.1371/journal.pone.0034233

83. Vieira S, Hiltensperger M, Kumar V, Zegarra-Ruiz D, Dehner C, Khan N, et al. Translocation of a gut pathobiont drives autoimmunity in mice and humans. Science (2018) 359:1156-61. doi: 10.1126/science.aar7201

84. Rother $\mathrm{N}$, and van der Vlag Disturbed $\mathrm{T}$ cell signaling and altered $\mathrm{Th} 17$ and regulatory $\mathrm{T}$ cell subsets in the pathogenesis of systemic lupus erythematosus. Front Immunol. (2015) 6:610. doi: 10.3389/fimmu.2015.00610

85. Vaghef-Mehrabany E, Alipour B, Homayouni-Rad A, Sharif S-K, AsghariJafarabadi M, Zavvari S. Probiotic supplementation improves inflammatory status in patients with rheumatoid arthritis. Nutrition (2014) 30:430-5. doi: 10.1016/j.nut.2013.09.007

86. Oreja-Guevara C, Ramos-Cejudo J, Aroeira LS, Chamorro B, Diez-Tejedor E. Th1/Th2 cytokine profile in relapsing-remitting multiple sclerosis patients treated with Glatiramer acetate or Natalizumab. BMC Neurol. (2012) 12:95. doi: 10.1186/1471-2377-12-95

87. Fleming J, Isaak A, Lee J, Luzzio C, Carrithers M, Cook T, et al. Probiotic helminth administration in relapsing-remitting multiple sclerosis: a phase 1 study. Mult Scler. (2011) 17:743-54. doi: 10.1177/1352458511398054

88. Kwon H, Kim G, Kim Y, Hwang W, Jash A, Sahoo A, et al. Amelioration of experimental autoimmune encephalomyelitis by probiotic mixture is mediated by a shift in T helper cell immune response. Clin Immunol. (2013) 146:217-27. doi: 10.1016/j.clim.2013.01.001

89. Uusitalo U, Liu X, Yang J, Aronsson C, Hummel S, Butterworth $\mathrm{M}$, et al. Association of early exposure of probiotics and islet autoimmunity in the TEDDY study. JAMA Pediatr. (2016) 170:20-8. doi: 10.1001/jamapediatrics.2015.2757

90. Koren O, Goodrich JK, Cullender TC, Spor A, Laitinen K, Backhed HK, et al. Host remodeling of the gut microbiome and metabolic changes during pregnancy. Cell (2012) 150:470-80. doi: 10.1016/j.cell.2012.07.008

91. Nuriel-Ohayon M, Neuman H, Koren O. Microbial changes during pregnancy, birth, and infancy. Front Microbiol. (2016) 7:1031. doi: 10.3389/fmicb.2016.01031

92. Astbury S, Mostyn A, Symonds ME, Bell RC. Nutrient availability, the microbiome, and intestinal transport during pregnancy. Appl Physiol Nutr Metab. (2015) 40:1100-6. doi: 10.1139/apnm-2015-0117

93. Vilson A, Ramadan Z, Li Q, Hedhammar A, Reynolds A, Julie S, et al. Disentangling factors that shape the gut microbiota in German Shepherd dogs. PLoS ONE (2018) 13:e0193507. doi: 10.1371/journal.pone.0193507

94. Dunlop AL, Mulle JG, Ferranti EP, Edwards S, Dunn AB, Corwin EJ. The maternal microbiome and pregnancy outcomes that impact infant health: a review. Adv Neonatal Care. (2015) 15:377-85. doi: 10.1097/ANC.0000000000000218

95. Vitali B, Cruciani F, Baldassarre ME, Capursi T, Spisni E, Valerii MC, et al. Dietary supplementation with probiotics during late pregnancy: outcome on vaginal microbiota and cytokine secretion. BMC Microbiol. (2012) 12:236. doi: 10.1186/1471-2180-12-236

96. Lindsay KL, Kennelly M, Culliton M, Smith T, Maguire OC, Shanahan F, et al. Probiotics in obese pregnancy do not reduce maternal fasting glucose: a double-blind, placebo-controlled, randomized trial (Probiotics in Pregnancy Study). Am J Clin Nutr. (2014) 99:1432-9. doi: 10.3945/ajcn.113.079723

97. Nitert MD, Barrett HL, Foxcroft K, Tremellen A, Wilkinson S, Lingwood $B$, et al. SPRING: an RCT study of probiotics in the prevention of gestational diabetes mellitus in overweight and obese women. BMC Pregnancy Childbirth. (2013) 13:50. doi: 10.1186/1471-2393-13-5

98. Dolatkhah N, Hajifaraji M, Abbasalizadeh F, Aghamohammadzadeh N, Mehrabi Y, Abbasi M. Is there a value for probiotic supplements in gestational diabetes mellitus? A randomized clinical trial. J Health Popul Nutr. (2015) 33:25. doi: 10.1186/s41043-015-0034-9

99. Zhou L, Xiao X. The role of gut microbiota in the effects of maternal obesity during pregnancy on offspring metabolism. Biosci Rep. (2018) 38:2. doi: 10.1042/BSR2017123
100. Mokkala K, Pussinen P, Houttu N, Koivuniemi E, Vahlberg T, Laitinen K. The impact of probiotics and n-3 long-chain polyunsaturated fatty acids on intestinal permeability in pregnancy: a randomised clinical trial. Benef Microbes. (2018) 9:199-208. doi: 10.3920/BM2017.0072

101. Jarde A, Lewis-Mikhael A-M, Moayyedi P, Stearns JC, Collins SM, Byene J, et al. Pregnancy outcomes in women taking probiotics or prebiotics: a systemic review and meta-analysis. BMC Pregnancy Childbirth. (2018) 18:14. doi: 10.1186/s12884-017-1629-5

102. Kriss JL, Ramakrishnan U, Beauregard JL, Phadke VK, Stein AD, Rivera JA, et al. Yogurt consumption during pregnancy and preterm delivery in Mexican women: a presopective analysis of interaction with maternal overweight status. Matern Child Nutr. (2017) 14:e12522. doi: $10.1111 / \mathrm{mcn} .12522$

103. Schminkey DL, Groer M. Imitating a stress response: a new hypothesis about the innate immune system's role in pregnancy. Med Hypotheses. (2014) 82:721-9. doi: 10.1016/j.mehy.2014.03.013

104. Mor G, Cardenas I, Abrahams V, Guller S. Inflammation and pregnancy: the role of the immune system at the implantation site. Ann N Acad Sci. (2011) 1221:80-7. doi: 10.1111/j.1749-6632.2010.05938.x

105. Bulmer JN, Williams PJ, Lash GE. Immune cells in the placental bed. Int J Dev Biol. (2010) 54:281-94. doi: 10.1387/ijdb.082763jb

106. Racicot K, Kwon J-Y, Aldo P, Silasi M, Mor G. Understanding the complexity of the immune system during pregnancy. Am J Reprod Immunol. (2014) 2014:72. doi: 10.1111/aji.12289

107. Faas MM, de Vos P. Uterine NK cells and macrophages in pregnancy. Placenta (2017) 56:44-52. doi: 10.1016/j.placenta.2017.03.001

108. Kimura M, and Nakayama T. Differentiation of NK1 and NK2 cells. Crit Rev Immunol. (2005) 25:361-74. doi: 10.1615/CritRevImmunol.v25.i5.20

109. Borzychowski AM, Croy BA, Chan WL, Redman CWG, Sargent IL. Changes in systemic type 1 and type 2 immunity in normal pregnancy and preeclampsia may be mediated by natural killer cells. Euro J Immunol. (2005) 35:3054-63. doi: 10.1002/eji.200425929

110. Ning F, Liu H, Lash GE. The role of decidual macrophages during normal and pathological pregnancy. Am J Reprod Immunol. (2016) 75:298-309. doi: 10.1111/aji.12477

111. Wu H-X, Jin L-P, Xu B, Liang S-S, Li D-J. Decidual stromal cells recruit Th17 cells into decidua to promote proliferation and invasion of human trophoblast cells by secreting IL-17. Cell Molec Immunol. (2014) 11:253-62. doi: 10.1038/cmi.2013.67

112. Saito S, Nakashima A, Shima T, Ito M. Th1/Th2/Th17 and regulatory Tcell paradigm in pregnancy. Am J Reprod Immunol. (2010) 63:601-10. doi: 10.1111/j.1600-0897.2010.00852.x

113. Rocca CL, Carbone F, Longobardi S, Matarese G. The immunology of pregnancy: regulatory $\mathrm{T}$ cells control maternal immune tolerance toward the fetus. Immunol Lett. (2014) 162(1 Pt A):41-8. doi: 10.1016/j.imlet.2014.06.013

114. Zelante T, Iannitti RG, Cunha C, De Luca A, Giovannini G, Pieraccini $\mathrm{G}$, et al. Tryptophan catabolites from microbiota engage aryl hydrocarbon receptor and balance mucosal reactivity via interleukin-22. Immunity. (2013) 39:372-85. doi: 10.1016/j.immuni.2013.08.003

115. Zelante T, Iannitti RG, Fallarino F, Gargaro M, De Luca A, Moretti S, et al. Tryptophan feeding of the IDO1-AhR axis in host-microbial symbiosis. Front Immunol. (2014) 5:640. doi: 10.3389/fimmu.2014.00640

116. Shinde R, Hezaveh K, Halaby MJ, Kloetgen A, Chakravarthy A, Medina T, et al. Apoptotic cell-induced AhR activity is required for immunological tolerance and suppression of systemic lupus erythematosus in mice and humans. Nat Immunol. (2018) 19:571-82. doi: 10.1038/s41590-018-0107-1

117. Rautava S, Collado MC, Salminen S, Isolauri E. Probiotics modulate host-microbe interaction in the placenta and fetal gut: a randomized, double-blind, placebo-controlled trial. Neonatology (2012) 102:178-84. doi: 10.1159/000339182

118. Ortiz-Andrellucchi A, Sanchez-Villegas A, Rodrguez-Gallego C, Lemes A, Molero T, Soria A, et al. Immunomodulatory effects of the intake of fermented milk with Lactobacillus casei DN114001 in lactating mothers and their children. Br J Nutr. (2008) 100:834-45. doi: 10.1017/S0007114508959183

119. Piccoli G, Rukhaimi MA, Liu Z-H, Zakharova E, Levin A. What we know and do not know about women and kidney diseases; questions unanswered 
and answers unquestioned: reflection on world kidney day and international woman's day. Braz J Med Biol Res. (2018) 23:199-209. doi: 10.1111/nep.13193

120. Pons-Estel G, Alarcon G, Scofield L, Reinlib L, Cooper G. Understanding the epidemiology and progression of Systemic Lupus Erythematosus. Semin Arthritis Rheum. (2010) 39:257-68. doi: 10.1016/j.semarthrit.2008.10.007

121. Carp H, Selmi C, Shoenfeld Y. The autoimmune bases of infertility and pregnancy loss. J Autoimmun. (2012) 38:J266-74. doi: 10.1016/j.jaut.2011.11.016

122. Chen J, Roberts C, Simpson J, March L. Pregnancy outcomes in women with rare autoimmune diseases. Arthritis Rheumatol. (2015) 67:3314-23. doi: 10.1002/art.39311

123. Gomes V, Mesquita A, Capela C. Autoimmune diseases and pregnancy: analysis of a series of cases. BMC Res Notes. (2015) 84:46-54. doi: 10.1186/s13104-015-1177-x

124. Moroni G, Ponticelli C. Pregnancy in women with systemic lupus erythematosus (SLE). Euro J Int Med. (2016) 32:7-12. doi: 10.1016/j.ejim.2016.04.005

125. Moroni G, Doria A, Giglio E, Tani C. Fetal outcome and recommendations of pregnancies in lupus nephritis in the 21st century. a prospective multicenter study. J Autoimmun. (2016) 74:6-12. doi: 10.1016/j.jaut.2016.07.010

126. Moroni G, Doria A, Giglio E, Imbasciati E, Tani C, Zen M, et al. Maternal outcome in pregnant women with lupus nephritis. a prospective multicenter study. J Autoimmun. (2016) 74:194-200. doi: 10.1016/j.jaut.2016. 06.012

127. Gianfreda D, Quaglini S, Frontini G, Raffiotta F, Messa P, Moroni G. Does pregnancy have any impact on long term damage accrual and on the outcome of lupus nephritis. J Autoimmun (2017) 84:46-54. doi: 10.1016/j.jaut.2017.06.003

128. Stout MJ, Conlon B, Landeau M, Lee I, Bower C, Zhao Q, et al. Identification of intracellular bacteria in the basal plate of the human placenta in term and preterm gestation. Am J Obstet Gynecol. (2013) 208:226.e1-7. doi: 10.1016/j.ajog.2013.01.018

129. Wassenaar T, Panigrahi P. Is a foetus developing in a sterile environment? Lett Appl Microbiol. (2014) 59:572-9. doi: 10.1111/lam.12334

130. Pantoja-Feliciano IG, Clemente JC, Costello EK, Perez ME, Blaser MJ, Knight $\mathrm{R}$, et al. Biphasic assembly of the murine intesinal microbiota during early development. ISME J. (2013) 7:1112-5. doi: 10.1038/ismej.2013.15

131. Indrio $F$, Neu J. The intestinal microbiome of infants and the use of probiotics. Curr Opin Pediatr. (2011) 23:145-50. doi: 10.1097/MOP.0b013e3283444ccb

132. Perez P, Dore J, Leclerc M, Levenez F, Benyacoub J, Serrant P, et al. Bacterial imprinting of the neonatal immune system: lessons from maternal cells? Pediatrics (2007) 119:e724-32. doi: 10.1542/peds.2006-1649

133. Jeurink P, van Bergenhenegouwen J, Jimenez E, Knippels L, Fernandez L, Garssen J, et al. Human milk: a source of more life than we imagine. Benef Microbes. (2013) 4:17-30. doi: 10.3920/BM2012.0040

134. Jimenez E, Marin M, Martin R, Odriozola J, Olivares M, Xaus J, et al. Is meconium from healthy newborns actually sterile? Res Microbiol. (2008) 159:187-93. doi: 10.1016/j.resmic.2007.12.007

135. de Andres J, Jimenez E, Chico-Calero I, Fresno M, Fernandez L, Rodriguez JM. Physiological translocation of lactic acid bacteria during pregnancy contributes to the composition of the milk microbiota in mice. Nutrients (2017) 10:1. doi: 10.3390/nu10010014

136. Mastromarino P, Capobianco D, Miccheli A, Pratico G, Campagna G, Laforgia N, et al. Administration of a multistrain probiotic product (VSL\#3) to women in the perinatal period differentially affects breast milk beneficial microbiota in relation to mode of delivery. Pharmacol Res. (2015) 95-96:6370. doi: 10.1016/j.phrs.2015.03.013

137. Dominguez-Bello M, Costello E, Contreras M, Magris M, Hidalgo G, Fierer $\mathrm{N}$, et al. Delivery mode shapes the acquisition and structure of the initial microbiota across multiple body habitats in newborns. Proc Natl Acad Sci USA. (2010) 107:11971-5. doi: 10.1073/pnas.1002601107

138. Ringel-Kulka T, Cheng J, Ringel Y, Salojarvi J, Carroll I, Plava A. Intestinal microbiota in healthy U.S. young children and adultsa high throughput microarray analysis. PLoS ONE (2013) 8:e64315. doi: 10.1371/journal.pone.0064315

139. Cox MJ, Huang YJ, Fujimura KE, Liu JT, McKean M, Boushey $\mathrm{HA}$, et al. Lactobacillus casei abundace is associated with profound shifts in the infant gut microbiome. PLoS ONE (2010) 5:e8745. doi: 10.1371/journal.pone.0008745

140. Rutten N, Gorissen D, Eck A, Niers L, Vlieger A, Besseling-van der Vaart I, et al. Long term development of gut microbiota composition in atopic children: impact of probiotics. PLoS ONE (2015) 10:e0137681. doi: 10.1371/journal.pone. 0137681

141. Kostic AD, Gevers D, Siljander H, Vatanen T, Hyotylainen T, Hamalainen A$\mathrm{M}$, et al. The dynamics of the human infant gut microbiome in development and in progression toward type 1 diabetes. Cell Hos Microbe. (2015) 17:26073. doi: $10.1016 /$ j.chom.2015.01.001

142. Grzeskowiak L, Gronlund M, Beckmann C, Salminen S, von Berg A, Isolauri E. The impact of perinatal probiotic intervention on gut microbiota: doubleblind placebo-controlled trials in Finland and Germany. Anaerobe (2012) 160:359-62. doi: 10.1016/j.anaerobe.2011.09.006

143. de Moreno de Le Blanc A, Dogi C, Galdeano C, Carmuega E, Weill R, Perdigon G. Effect of the administration of a fermented milk containing Lactobacillus casei DN-114001 on intestinal microbiota and gut associated immune cells of nursing mice and after weaning until immune maturity. BMC Immunol. (2008) 9:27. doi: 10.1186/1471-2172-9-27

144. Miao R, Zhu X, Wan C, Wang Z, Wen Y, Li Y. Effect of Clostridium butyricum supplementation on the development of intestinal flora and the immune system of neonatal mice. Exp Ther Med. (2018) 15:1081-6. doi: 10.3892/etm.2017.5461

145. Luoto R, Kalliomaki M, Laitinen K, Isolauri E. The impact of perinatal probiotic intervention on the development of overweight and obesity: follow-up study from birth to 10 years. Int J Obes. (2010) 34:1531-7. doi: $10.1038 /$ ijo. 2010.5

146. Sawh SC, Deshpande S, Jansen S, Reynaert CJ, Jones PM. Prevention of necrotizing enterocolitis with probiotics: a systematic review and meta analysis. Peer J. (2016) 4:e2429. doi: 10.7717/peerj.2429

147. Stappenbeck TS, Hooper LV, Gordon JI. Developmental regulation of intestinal angiogenesis by indigenous microbes via paneth cells. Proc Natl Acad Sci USA. (2002) 99:15451-5. doi: 10.1073/pnas.202604299

148. Miccoli A, Gioacchini G, Maradonna F, Benato F, Tatjana S, and Carnevali O. Beneficial bacteria affect Danio rerio development by the modulation of maternal factors involved in autophagic apoptotic and dorsalizing processes. Cell Physiol Biochem. (2015) 35:1706-18. doi: 10.1159/000373983

149. Guilmot A, Hermann E, Braud V, Carlier Y, Truyens C. Natural killer cell respones to infections in early life. J Innate Immun. (2011) 3: 280-8. doi: $10.1159 / 000323934$

150. Kollmann TR, Crabtree J, Rein-Weston A, Blimkie D, Thommai F, Wang $\mathrm{XY}$, et al. Neonatal innate TLR-mediated responses are distinct from those of adults. J Immunol. (2009) 183:7150-60. doi: 10.4049/jimmunol.0901481

151. Ygberg S, and Nilsson A. The developing immune system - from foetus to toddler. Acta Paediatr. (2011) 101:120-7. doi: 10.1111/j.1651-2227.2011.02494.x

152. Sautois B, Fillet G, Beguin Y. Comparative cytokine production by in vitro stimulation mononucleated cells from cord blood and adult blood. Exp Hematol. (1997) 25:103-8.

153. Parker GA, Picut CA, Swanson C, Toot JD. Histologic features of postnatal development of immune system organs in the Sprague-Dawley rat. Toxicol Pathol. (2015) 43:794-815. doi: 10.1177/0192623315578720

154. Brandtzaeg P. The mucosal immune system and its integration with the mammary glands. J Pediatr. (2010) 156(Suppl. 2):S8-15. doi: 10.1016/j.jpeds.2009.11.014

155. Kramer D, Cebra J. Early appearance of "natural" mucosal IgA responses and germinal centers in suckling mice developing in the absence of maternal antibodies. J Immunol. (1995) 154:2051-62.

156. de Aguero M, Ganal-Vonarburg S, Fuhrer T, Rupp S, Uchimura Y, Li H, et al. The maternal microbiota drives early postnatal innate immune development. Science (2016) 351:1296-302. doi: 10.1126/science.aad2571

157. Yajima M, Nakayama M, Hatano S, Yamazaki K, Aoyama Y, Yajima T, et al. Bacterial translocation in neonatal rats: the relation between intestinal flora, translocated bacteria, and influence of milk. J Pediatr Gastroenterol Nutr. (2001) 33:592-601. doi: 10.1097/00005176-200111000-00015

158. Toomer OT, Ferguson M, Pereira M, Do A, Bigley E, Gaines D, et al. Maternal and postnatal dietary probiotic supplementation enhances splenic regulatory $\mathrm{T}$ helper cell population and reduces peanut allergen-induce 
hypersensitivity responses in mice. Immunobiology (2014) 219:661-70. doi: 10.1016/j.imbio.2014.03.019

159. Rø ADB, Simpson MR, Rø TB, Storrø O, Johnsen R, Videm V, et al. Reduced Th22 cell proportion and prevention of atopic dermatitis in infants following maternal probiotic supplementation. Clin Exp Allergy. (2017) 47:1014-21. doi: 10.1111/cea.12930

160. Moya-Perez A, Perez-Villalba A, Benitez-Paez A, Campillo I, Sanz Y. Bifidobacterium CECT 7765 modulates early stress-induced immune, neuroendocrine and behavioral alterations in mice. Brain Behav Immun. (2017) 65:43-56. doi: 10.1016/j.bbi.2017.05.011

161. Nordqvist M, Jacobsson B, Brantsaeter A, Myhre R, Nilsson S, Sengpiel $\mathrm{V}$. Timing of probiotic milk consumption during pregnancy and effects on the incidence of preeclampsia and preterm delivery: a prospective observational cohort study in Norway. BMJ Open (2018) 8:e018021. doi: 10.1136/bmjopen-2017-018021

162. Zuccotti G, Meneghin F, Aceti A, Barone G, Callegari M, Di Mauro A, et al. Probiotics for prevention of atopic diseases in infants: systemic review and meta-analysis. (2015) 70:1356-1371. doi: 10.1111/all.12700
163. Savilahti EM, Ilonen J, Kukkonen AK, Savilahti E, Kuitunen M. (2018). Celiac disease by the age of 13 years is not associated with probiotics administration in infancy. $J$ Pediatr Gastroenterol Nutr. 66:937-40. doi: 10.1097/MPG.0000000000001846

164. Mueller NT, Bakacs E, Combellick J, Grigoryan Z, Dominguez-Bello MG The infant microbiome development: mom matters. Trends Mol Med. (2015) 21:109-17. doi: 10.1016/j.molmed.2014.12.00

Conflict of Interest Statement: The authors declare that the research was conducted in the absence of any commercial or financial relationships that could be construed as a potential conflict of interest.

Copyright (c) 2018 Swartwout and Luo. This is an open-access article distributed under the terms of the Creative Commons Attribution License (CC BY). The use, distribution or reproduction in other forums is permitted, provided the original author(s) and the copyright owner(s) are credited and that the original publication in this journal is cited, in accordance with accepted academic practice. No use, distribution or reproduction is permitted which does not comply with these terms. 